\title{
Analyzing Bio-Geo-Chemical Factors in Relation to Land Use Trends on Basalt Terrain in Dong Nai and Nearby Areas
}

\author{
Dang Kinh Bac*, Dang Van Bao \\ VNU University of Science, Vietnam National University, Hanoi, 334 Nguyen Trai, Hanoi, Vietnam \\ Received 15 January 2020 \\ Revised 16 February 2020; Accepted 18 February 2020

\begin{abstract}
Basalt terrain is widely distributed in the Central Highlands and Southeast of Vietnam. Currently, land use policies on basalt types are not really suitable, affecting economic growth and creating negative impacts on the environment, especially soil and water pollution. This study carried out the assessment of bio-geochemical conditions in three types of basalt terrain, using 16 remote sensing indices. The relationship between these indices is analyzed based on correlation matrix and structural equation model (SEM). The results show different land use management trends across the three basalt types. The results encourage the land-use management to (i) expand and maintain the protected forests on Miocene basalt; (ii) develop agriculture on the Pliocene - Pleistocene basalt terrain; and (iii) improve soil quality and ecotourism on late Pleistocene basalt terrain.
\end{abstract}

Keywords: Basalt terrain, bio-geo-chemical factor, remote sensing index, structural equation model, Dong Nai.

\footnotetext{
* Corresponding author.

E-mail address: dangkinhbac@hus.edu.vn 


\title{
Phân tích các yếu tố sinh-địa-hóa trong mối liên quan với xu hướng sử dụng đất trên địa hình bazan khu vực Đồng Nai và phụ cận
}

\author{
Đặng Kinh Bắc*, Đặng Văn Bào \\ Truờng Đại học Khoa học Tụ nhiên, Đại học Quốc gia Hà Nội, 334 Nguyễn Trãi, Hà Nội, Việt Nam \\ Nhận ngày 15 tháng 01 năm 2020 \\ Chỉnh sửa ngày 16 tháng 02 năm 2020; Chấp nhận đăng ngày 18 tháng 02 năm 2020
}

\begin{abstract}
Tóm tắt: Địa hình bazan phân bố khá rộng rãi ở Tây Nguyên và Đông Nam Bộ. Hiện tại, chính sách sử dụng đất trên các loại địa hình bazan chưa thực sự phù hợp, ảnh hưởng tới sự tăng trưởng kinh tế và tạo ra những tác động tiêu cực đến môi trường, đặc biệt là suy thoái đất và nguồn nước. Nghiên cứu này thực hiện việc đánh giá điều kiện sinh-địa-hóa trên ba loại địa hình bazan, thông qua 16 chỉ số viễn thám. Mối quan hệ giữa các chỉ số này được phân tích dựa trên ma trận tương quan và mô hình phương trình cấu trúc (SEM), phản ánh các xu hướng sử dụng đất khác nhau trên ba loại địa hình bazan. Các kết quả nghiên cứu khuyến khích việc quản lý, sử dụng đất theo các hướng i) mở rộng và duy trì các khu rừng được bảo vệ trên địa hình bazan Miocen; ii) phát triển nông nghiệp trên địa hình bazan Pliocen - Pleistocen giữa; và iii) cải thiện đất và phát triển du lịch sinh thái trên địa hình bazan Pleistocen muộn.
\end{abstract}

Tư khoá: Địa hình bazan, sinh-địa-hóa, chỉ số viễn thám, mô hình phương trình cấu trúc, Đồng Nai.

\section{Mở đầu}

Bazan Kainozoi ở Việt Nam chiếm diện tích 23.000 km², phân bố tập trung ở Tây Nguyên, Trung Bộ và Đông Nam Bộ (khoảng 20.000 $\mathrm{km}^{2}$ ). Trên các vùng khác, bazan chỉ phân bố trên các diện tích nhỏ ở Điện Biên, Lai Châu, tây Thanh Hóa và Nghệ An. Địa hình baazan có nhiều lợi thế trong công tác bảo tồn và phát triển kinh tế - xã hội [1,2]. Bazan được phun trào trên bề mặt Trái Đất theo nhiều thời kỳ, trong các điều kiện tự nhiên khác nhau (đặc biệt là địa hình, khí hậu và lớp phủ thực vật), do vậy có các đặc điểm riêng về sinh - địa - hóa. Điều kiện sinh - địa - hóa của các khối bazan là yếu tố quan trọng để nhận dạng có tính định lượng về thành phần vật chất của chúng. Cho tới nay, việc nghiên cứu đặc điểm khác biệt của các yếu tố này giữa các loại địa hình bazan vẫn chưa được làm rõ. Điều này dẫn tới việc sử dụng địa hình bazan chưa thật hiệu quả, các chính sách sử dụng đất ở đây chưa khuyến khích người dân địa phương phát triển các lĩnh vực kinh tế - xã hội phù hợp, không chỉ làm chậm tăng trưởng kinh tế mà còn dẫn đến những tác động tiêu cực đến môi trường [3]. Ví dụ, lớp đất màu mỡ hình thành trên đá bazan bị bóc đi do hoạt động khai thác bauxite phải trải qua khoảng thời gian dài mới phục hồi được [4]. Nhiều khu vực rừng nguyên sinh được chuyển đổi thành đất nông nghiệp, dẫn đến sự gia tăng xói mòn đất, các mối nguy hại cho hệ sinh thái tự nhiên [5]. Do đó, việc hiểu rõ điều kiện tự nhiên, kinh tế - xã hội thông qua phân tích các nhân tố sinh-địa-hóa trên địa hình bazan

\footnotetext{
* Tác giả liên hệ.

Địa chỉemail: dangkinhbac@hus.edu.vn

https://doi.org/10.25073/2588-1094/vnuees.4542
} 
sẽ là một trong các cơ sở khoa học quan trọng cho đề xuất định hướng quản lý, sử dụng đất phù hợp và đưa ra phản hồi/thay đồi chính sách sử dụng đất tại địa phương kịp thời và hiệu quả.

Công nghệ viễn thám là công cụ hữu hiệu trong giám sát các quá trình sinh-địa-hóa trên các đối tượng tự nhiên khác nhau và đánh giá những tác động của con người lên Trái Đất từ cấp địa phương đến toàn cầu [6]. Viễn thám và GIS đã được sử dụng rộng rãi trong các lĩnh vực nông nghiệp, môi trường và đánh giá sinh thái [7]. Phân tích viễn thám đa thời gian và GIS cho phép xác định các xung đột giữa lợi ích kinh tế - môi trường và chính sách sử dụng đất. Qua đó, các nhà quản lý có thể điều chỉnh và cải thiện các chính sách kịp thời. Ngoài ra, các chỉ số viễn thám được sử dụng làm chỉ thị cho nhiều đối tượng trong tự nhiên. Ví dụ: chỉ số xây dựng được sử dụng để đánh giá sự mở rộng của đô thị [8], trong khi hàm lượng chất diệp lục trong lá được tính từ dữ liệu Sentinel-2 có thể được sử dụng để đánh giá sức khỏe cây trồng [9]. Với tính đa dụng trong đánh giá chính sách, đặc điểm tự nhiên, kinh tế - xã hội và sử dụng đất, các chỉ số viễn thám hoàn toàn có thể giúp đơn giản hóa hệ thống sinh khí hậu của các loại địa hình bazan khác nhau [10,11].

Nghiên cứu này tập trung đánh giá đặc điểm sinh-địa-hóa trên 3 thành tạo bazan phân bố ở tỉnh Đồng Nai và lân cận thông qua 16 chỉ số viễn thám. Mối quan hệ giữa 16 chỉ số này sẽ được phân tích qua mô hình phương trình cấu trúc (Structural Equation Models-SEM). Kết quả nghiên cứu giúp làm rõ mối quan hệ giữa nền vật chất, sinh-khí hậu tới xu thế sử dụng đất trong các loại bazan, qua đó có thể đánh gía được mức độ hợp lý trong việc áp dụng các chính sách sử dụng đất đối với các loại địa hình bazan khác nhau.

\section{Khu vực nghiên cứu}

Nhằm làm rõ khả năng sử dụng mô hình phương trình cấu trúc trong đánh giá đặc điểm sinh-địa-hóa trên các thành tạo bazan, mối liên quan của chúng với xu hướng sử dụng đất, nghiên cứu này chọn không gian nghiên cứu là tỉnh Đồng Nai - nơi địa hình bazan có sự phân bố rộng rãi, hầu như đầy đủ các loại địa hình bazan ở Việt Nam. Để so sánh, liên kết, khu vực nghiên cứu cũng được mở rộng ra các tỉnh lân cận. Ba loại địa hình bazan được phân loại và sử dụng gồm: bazan Miocen, bazan Pliocen- Pleistocen giữa và bazan Pleistocen muộn (Hình 1).

Núi lửa Kainozoi và địa hình dung nham bazan ở Việt Nam được hình thành chủ yếu vào Miocen (5,3-23 triệu năm trước), Pliocen Pleistocen sớm (0,78-5,3 triệu năm trước), Pleistocen giữa $(0,125-0,78$ triệu năm trước) và Pleistocen muộn-Holocen $(0,125$ triệu năm trước đến nay). Đợt phun trào gần nhất được biết tới là ở đảo Tro (Hòn Đồ) thuộc vùng biển tỉnh Bình Thuận vào năm 1923. Trên các bản đồ địa chất tỷ lệ 1:200.000, các thế hệ bazan lần lượt được xếp vào các hệ tầng Đại $\mathrm{Nga}\left(\mathrm{N}_{2} đ n\right)$, Túc Trưng $\left(\mathrm{N}_{2}-\mathrm{Q}_{1}{ }^{1} t t\right)$, Xuân Lộc $\left(\mathrm{Q}_{1}{ }^{2} x l\right)$ và Phước Tân $\left(\mathrm{Q}_{1}{ }^{3}\right.$ $p t$ ). Việc xác định bazan hệ tầng Đại Nga tuổi Miocen dựa trên cơ sở hầu hết các mẫu phân tích tuổi tuyệt đối trên các bazan này đều cho giá trị trên 5,3 triệu năm cách ngày nay. Trên các bản đồ địa chất tỷ lệ 1:50.000 khu vực Đồng Nai, các phun trào bazan hệ tầng Đại Nga cũng đã được xếp vào Miocen [12].

Theo các bản đồ địa chất tỷ lệ 1:50.000, tỉnh Đồng Nai có đủ 4 thành tạo bazan như đề cập ở trên. Bazan hệ tầng Đại Nga phân bố ở phía tây bắc khu vực nghiên cứu, tại bề mặt đỉnh ở độ cao trên $150 \mathrm{~m}$. Đá bazan bị phong hóa mạnh, tạo vỏ laterit bauxite, tương tự như vỏ phong hóa tại Đắk Nông, Bảo Lộc. Quá trình xâm thực mạnh dọc các khe suối đã bóc đi lớp phủ bazan, lộ ra các trầm tích hệ tầng La Ngà tuổi Jura $\left(\mathrm{J}_{2} \ln \right)$ nơi đây. Khác với địa hình trên bazan hệ tầng Đại Nga tại Đắk Nông và Lâm Đồng, nơi đã được khai phá từ lâu đời cho phát triển nông nghiệp với các cây công nghiệp dài ngày như cà phê, chè, hồ tiêu, cao su và hiện nay là khai thác nhôm (Nhân Cơ, tỉnh Đăk Nông và Tân Rai, tỉnh Lâm Đồng), trên hầu hết diện tích địa hình bazan hệ tầng Đại $\mathrm{Nga}$ ở Đồng Nai hiện vẫn còn rừng nguyên sinh [3]. 


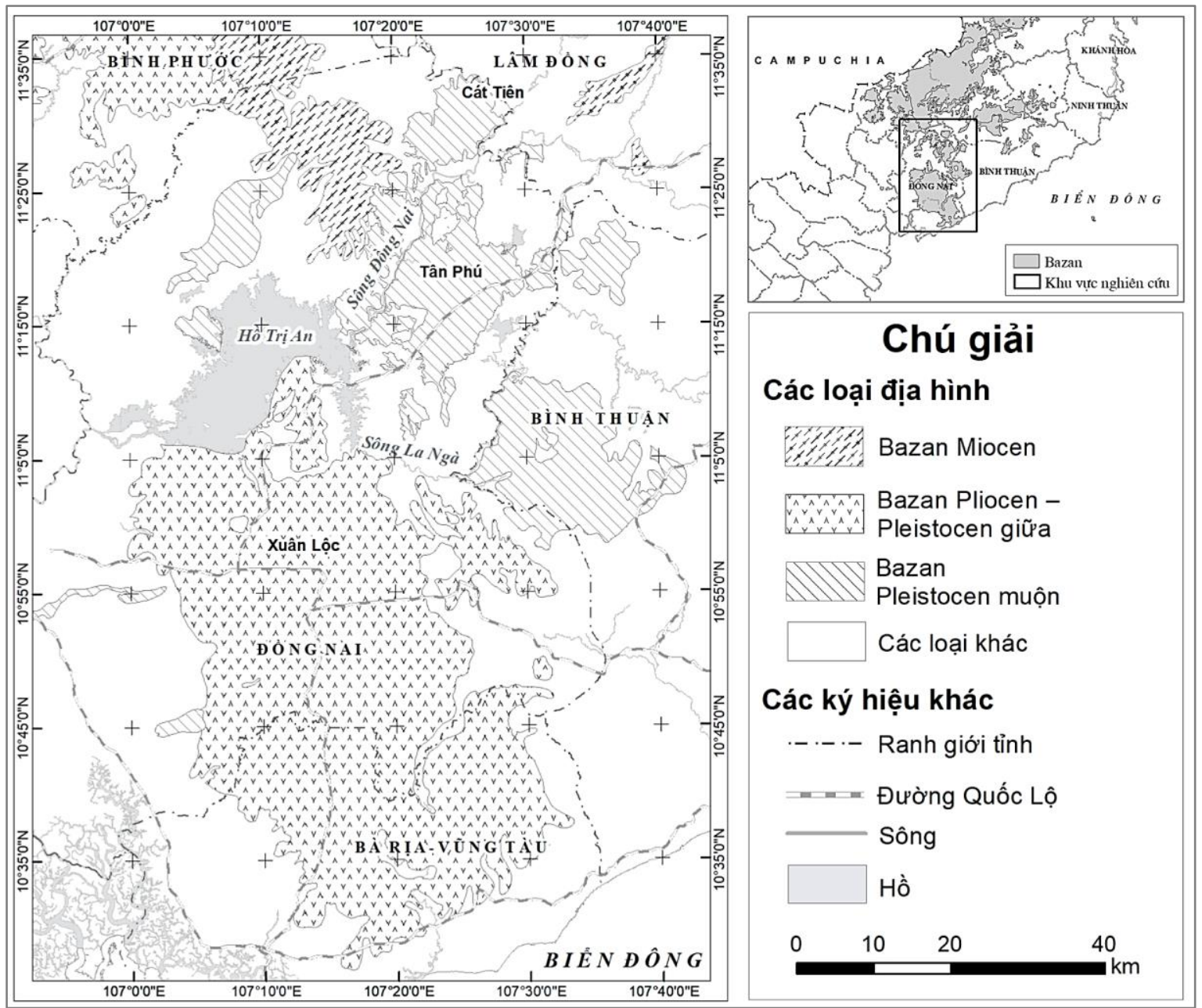

Hình 1. Khu vực nghiên cứu với 3 loại địa hình bazan (nguồn: [12]).

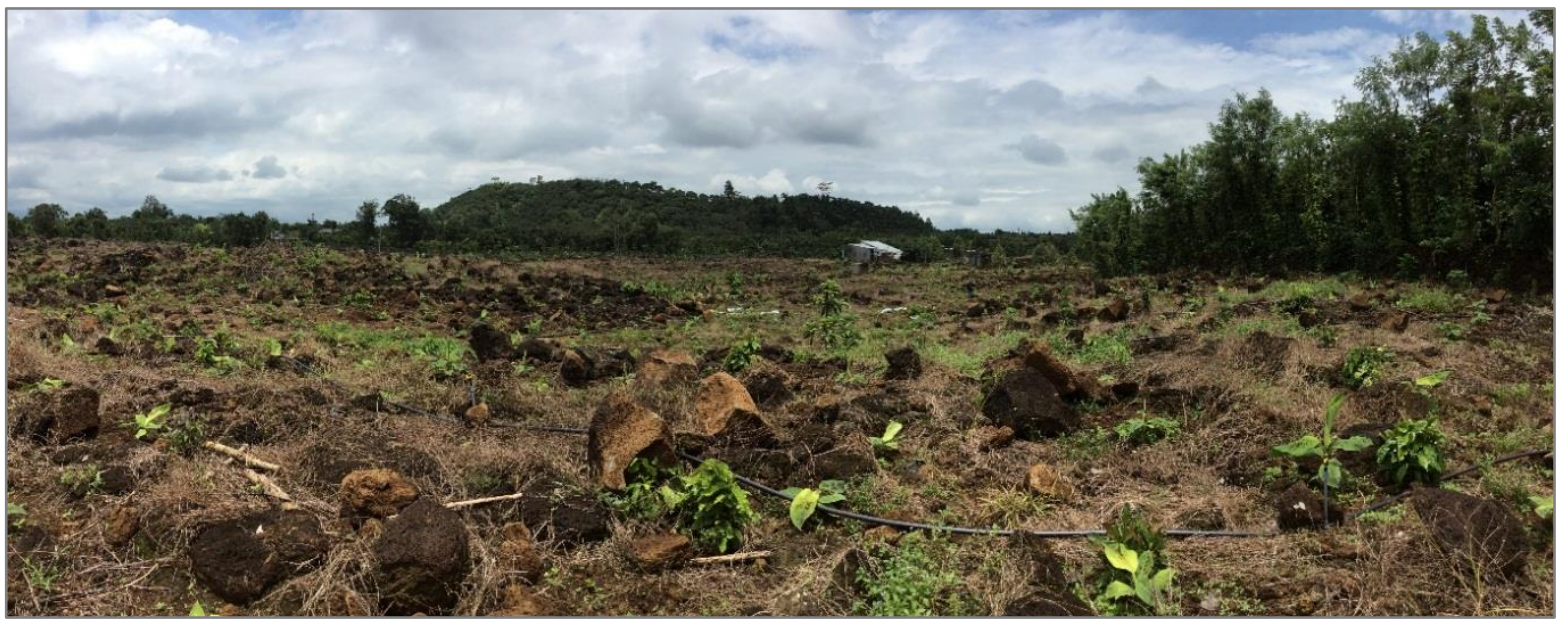

Hình 2. Cảnh quan bazan Pleistocen muộn, hệ tầng Phước Tân tại Tân Phú, Đồng Nai (ảnh Đặng Văn Bào). 
Bazan hệ tầng Túc Trưng phân bố trên diện tích nhỏ ở phía đông nam hồ Trị An. Bazan hệ tầng Xuân Lộc có diện phân bố rộng rãi nhất trong phạm vi tỉnh Đồng Nai, chúng tạo nên địa hình dạng vòm với nhiều miệng núi lửa được bảo tồn tốt. Các bazan Túc Trưng và Xuân Lộc trong phạm vi tỉnh Đồng Nai đều bị phong hóa mạnh, cho tầng đất đỏ dày trên $10 \mathrm{~m}$, đã được sử dụng trồng cây công nghiệp dài ngày từ lâu đời. Có thể nhận thấy các đặc điểm địa hình, vỏ phong hóa và hiện trạng sử dụng đất trên các thành tạo bazan hai hệ tầng Túc Trưng và Xuân Lộc tại Đồng Nai không có sự khác biệt đáng kể. Cũng nhận thấy rằng, không chỉ ở Đồng Nai, tại các vùng phân bố địa hình bazan rộng lớn như Gia Lai, Buôn Ma Thuột, việc phân biệt các đặc trưng trên của hai loại bazan cũng khá khó khăn. Trong bài viết này, hai loại địa hình trên bazan hệ tầng Túc Trưng và Xuân Lộc được nhóm gộp thành một loại là địa hình bazan Pliocen Pleistocen giữa.

Bazan hệ tầng Phước Tân là sản phẩm của hoạt động núi lửa trẻ nhất ở Việt Nam, phân bố chủ yếu trong phạm vi tỉnh Đồng Nai, các diện tích hẹp hơn được xác định tại Chư B'luk (Krông Nô, Đắk Nông) và Sông Lũy (Bình Thuận). Phun trào hệ tầng Phước Tân phân bố ở địa hình thấp, chảy tràn theo các thung lũng cổ. Tại một số nơi, các dòng dung nham bazan chặn ngang lòng sông Đồng Nai, sông La Ngà và hình thành ở phía trên chúng các hồ, đầm lầy. Vùng đầm lầy Cát Tiên tạo nên Khu bảo tồn/Vườn quốc gia Cát Tiên hiện nay là dấu vết còn lại của hoạt động phun trào tạo đập chắn tự nhiên trên sông Đồng Nai của bazan hệ tầng Phước Tân. Hoạt động phong hóa trên bazan hệ tầng Phước Tân mới ở giai đoạn đầu, hầu hết các diện lộ đều gặp cảnh quan hoang mạc đá. Các tảng đá bazan phân bố trên bề mặt địa hình như còn nguyên hình dạng của dòng chảy dung nham bazan nguyên sinh. Vỏ phong hóa và các tầng đất mỏng chỉ phân bố dọc theo các khe nứt (Hình 2). Đặc điểm địa hình và vỏ phong hóa trên bazan hệ tầng Phước Tân cho thấy phun trào bazan này còn khá trẻ, có thể chỉ trong Holocen. Cũng trên phạm vi phân bố bazan hệ tầng Phước Tân hiện đã phát hiện nhiều hang động dung nham có ý nghĩa khoa học và thực tiễn. Đồng thời với việc nghiên cứu, đánh giá các yếu tố sinh - địa - hóa cho định hướng sử dụng đất hợp lý, tính đa dạng, độc đáo của địa hình bazan ở phía bắc Đồng Nai có thể là cơ sở cho việc nghiên cứu, đề xuất xây dựng công viên địa chất toàn cầu tại đây.

\section{Phương pháp nghiên cứu}

Nghiên cứu sử dụng 3 loại dữ liệu ảnh viễn thám: Landsat, Sentinel-2 và MODIS chụp năm 2018, là dữ liệu đầu vào chính trong tính toán 16 chỉ số viễn thám (được nêu ở Bảng 1). Trong 16 chỉ số viễn thám, 7 chỉ số vật chất hóa học (gồm chỉ số số $1,2,3,4,5,6$, và 7 ); 4 chỉ số sinh học (gồm $8,14,15$, và 16 ); và 5 chỉ số địa lý (gồm 9 , $10,11,12$ và 13$)$. Toàn bộ dữ liệu viễn thám được xử lý lọc nhiễu và đưa về cùng một hệ tọa độ là UTM, WGS-84, múi 48 trên phần mềm ArcGIS. Mỗi pixel ảnh sau đó được chuyển đổi sang dạng điểm để đưa vào đánh giá thống kê. Kết quả tính toán được kiểm chứng trong các đợt khảo sát thực địa vào tháng $12 / 2017$ và tháng 10/2018.

Sau khi các chỉ số viễn thám được tính toán, nghiên cứu áp dụng mô hình phương trình cấu trúc (Structural Equation Model - SEM) nhằm tái hiện lại mối quan hệ giữa các biến sinh-địa-hóa bên trong ba loại hình bazan. Mô hình phương trình cấu trúc là một kỹ thuật phân tích thống kê đa biến, được sử dụng để phân tích các mối quan hệ cấu trúc giữa các biến đầu vào. Kỹ thuật này là sự kết hợp giữa phân tích nhân tố và phân tích hồi quy bội, được sử dụng để phân tích mối quan hệ cấu trúc giữa các biến đo chỉ số viễn thám và cấu trúc tiềm ẩn. Mô hình SEM kết hợp các kỹ thuật như hồi quy đa biến, phân tích nhân tố và phân tích mối quan hệ tương hỗ (giữa các phần tử theo sơ đồ mạng) cho phép người dùng kiểm tra mối quan hệ nhân quả trong mô hình. Phương pháp này được các nhà nghiên cứu sinh thái và địa lý ưa thích vì nó ước tính được sự phụ thuộc nhiều và liên quan giữa các đối tượng sinh-địahóa trong một phân tích duy nhất [13]. Trong nghiên cứu này, hai loại biến được sử dụng là 
biến nội sinh và biến ngoại sinh. Các biến nội sinh tương đương với các biến phụ thuộc và bằng với biến độc lập. Các biến nội sinh được xét đến bao gồm thành phần vật chất bên trong lớp vỏ thổ nhưỡng như lượng sắt, nhôm và silicate, đóng vai trò quyết định tới hàm lượng dinh dưỡng và khả năng giữ nước trong đất. Các nhân tố ngoại sinh như nhiệt độ, mưa và bức xạ nhiệt và các tác động từ con người sẽ thúc đẩy quá trình phong hóa, biến đổi sử dụng đất và thay đổi sức khỏe cây trồng. Các thông tin trên sẽ được tích hợp trong mô hình SEM, được trình bày trong mục 4.3 .

Bảng 1. Các chỉ số viễn thám được sử dụng để tái hiện lại các biến sinh-địa-hóa tại khu vực bazan

\begin{tabular}{|c|c|c|c|c|}
\hline STT & Chỉ số viễn thám & Ký hiệu & Công thức tương ứng & $\begin{array}{c}\text { Ảnh vệ } \\
\text { tinh }\end{array}$ \\
\hline 1 & Sắt (II) & $\mathrm{Fe} 2+$ & $\frac{\text { SWIR_2 }}{\text { Near_Infrared }}+\frac{\text { Green }}{\text { Red }}$ & \multirow{11}{*}{ Landsat 8} \\
\hline 2 & Sắt (III) & $\mathrm{Fe} 3+$ & Red/Green & \\
\hline 3 & Oxit sắt (III) & $\mathrm{Fe} 2 \mathrm{O} 3$ & SWIR_1/Near_Infrared & \\
\hline 4 & Laterite & Laterite & $S W I R_{-} 1 / S W I R_{-} 2$ & \\
\hline 5 & Carbonate & Carbonat & $T I R S \_1 / T I R S \_2$ & \\
\hline 6 & Silicate & $\mathrm{Si}$ & $S W I R \_2 / S W I R \_1$ & \\
\hline 7 & Chỉ số kích thước hạt trên bề mặt & GSI & $\begin{array}{c}(\text { Red - Blue }) * \\
(\text { Red + Blue + Green })\end{array}$ & \\
\hline 8 & Chỉ số lớp vỏ sinh học & $\mathrm{CI}$ & $1-\frac{\text { Red }- \text { Blue }}{\text { Red }+ \text { Blue }}$ & \\
\hline 9 & Chỉ số mặt nước & NDWI & $\frac{N I R-S W I R_{-} 1}{N I R+S W I R_{-} 1}$ & \\
\hline 10 & Chỉ số khác biệt cây trồng & NDVI & $\frac{N I R-R E D}{N I R+R E D}$ & \\
\hline 11 & Chỉ số xây dựng & $\mathrm{BU}$ & $\frac{S W I R_{-} 1-N I R}{S W I R_{-} 1+N I R}-\frac{N I R-R E D}{N I R+R E D}$ & \\
\hline 12 & Nhiệt độ & Temp & \multirow{2}{*}{ Nguồn: WorldClim ${ }^{1}$} & \multirow{2}{*}{ MODIS } \\
\hline 13 & Lượng mưa & Prep & & \\
\hline 14 & $\begin{array}{l}\text { Phân số của bức xạ hoạt động tổng } \\
\text { hợp ảnh }\end{array}$ & FAPAR & \multirow{3}{*}{$\begin{array}{c}\text { Tính toán bằng công cụ SENTINEL- } \\
2 \text { Toolbox level-2 được phát triển } \\
\text { bởi ESA }{ }^{2}\end{array}$} & \multirow{3}{*}{ Sentinel-2 } \\
\hline 15 & Chỉ số vùng lá & LAI & & \\
\hline 16 & Phân số lớp phủ & FVC & & \\
\hline
\end{tabular}

\footnotetext{
${ }^{1}$ http://www.worldclim.org

${ }^{2}$ https://earth.esa.int/web/guest/home
} 


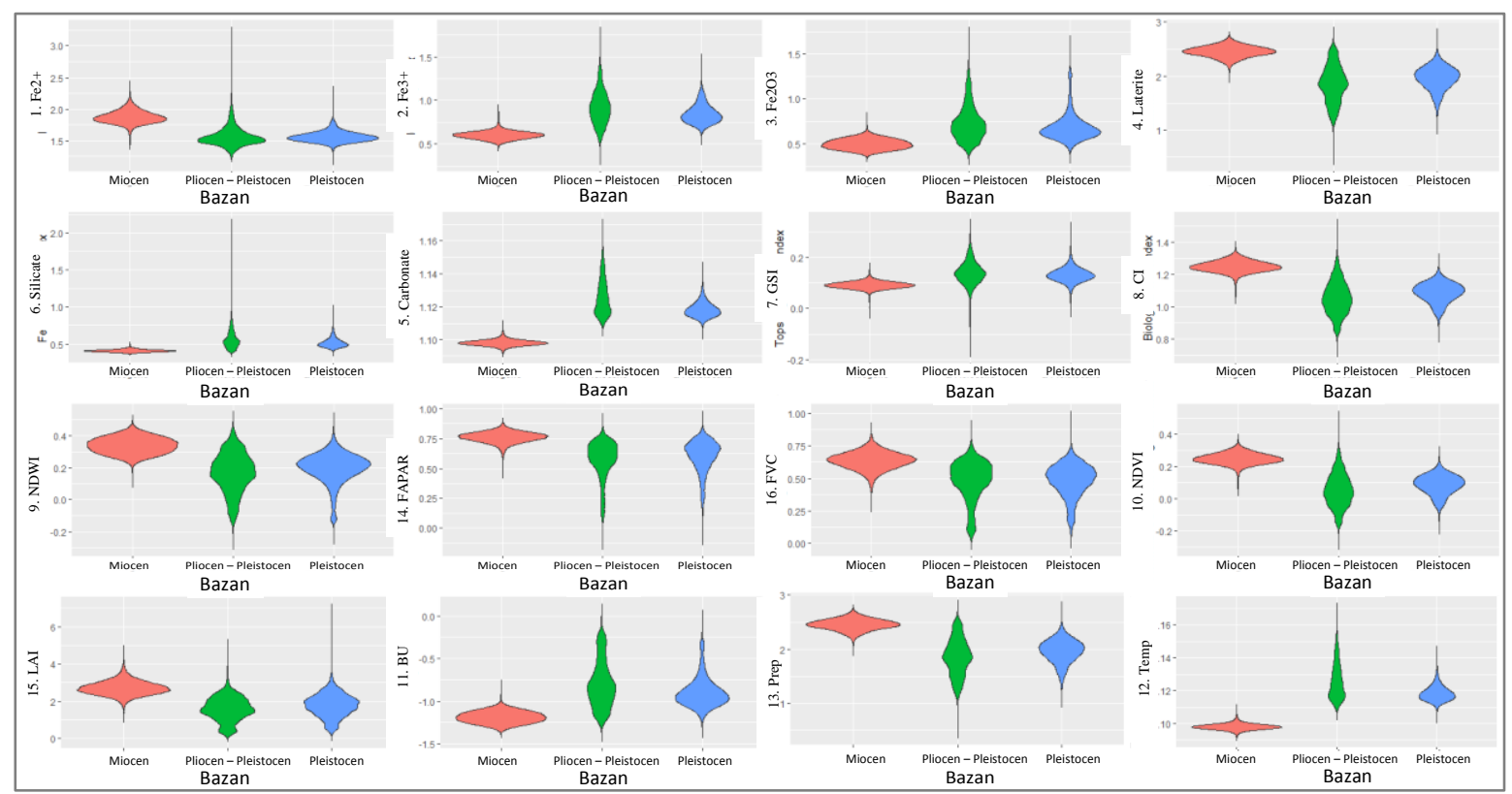

Hình 3. Biểu đồ của 16 tham số tự nhiên được phân tách trong ba loại địa hình bazan.

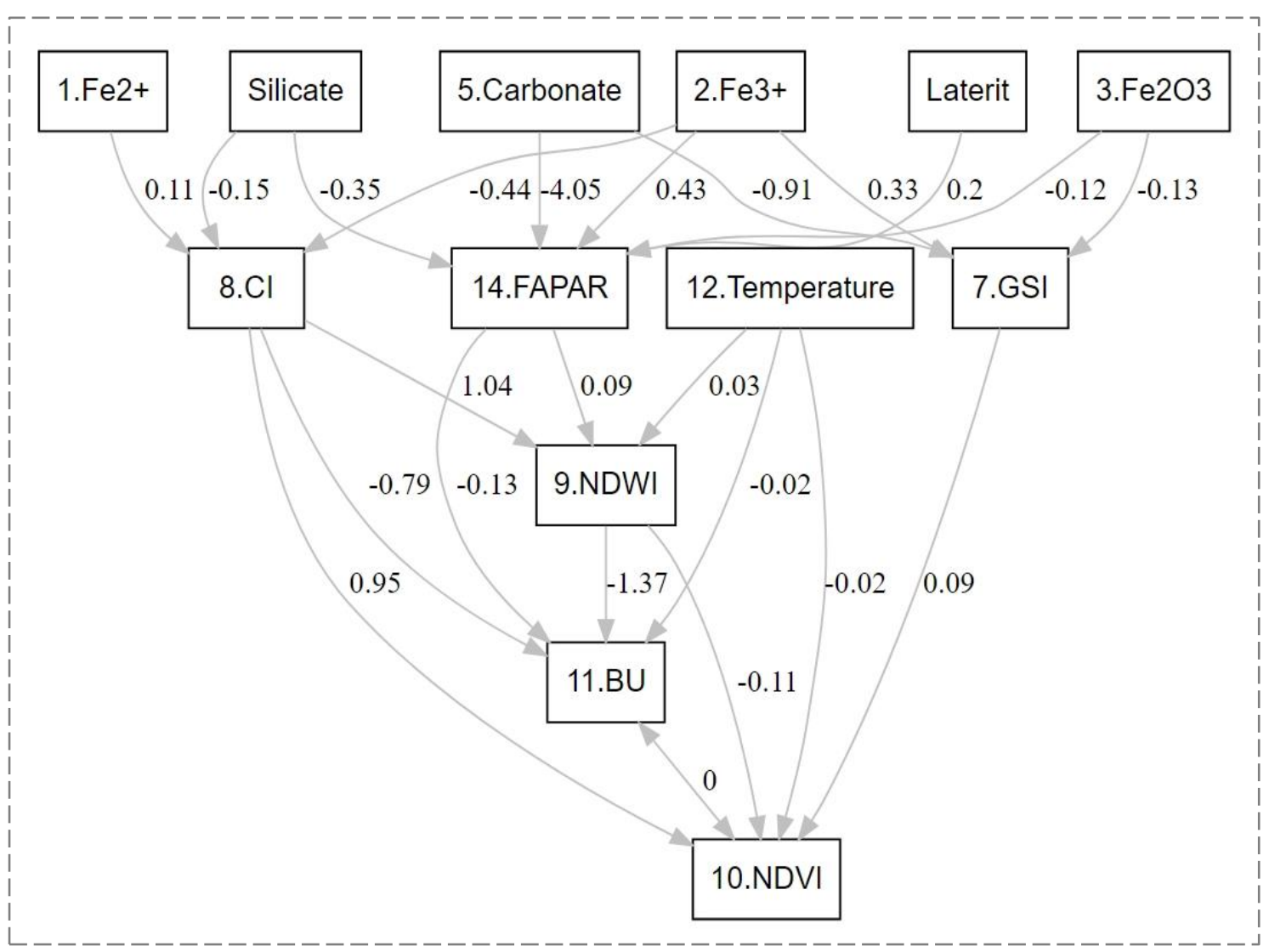

Hình 4. Mô hình công thức cấu trúc (SEM) kết nối các yếu tố sinh-địa-hóa trên thành tạo bazan. 


\section{Kết quả và thảo luận}

\section{1. Đặc điểm sinh-địa-hóa trên ba loại địa hình bazan}

Sự phân bố của 16 tham số sinh-địa-hóa trong ba loại địa hình bazan được thể hiện trên Hình 3. Nhìn chung, đặc điểm sinh - địa - hóa của địa hình bazan Miocen được phân biệt rõ ràng với hai loại địa hình bazan còn lại. Các giá trị viễn thám của Fe (II), laterit, CI, NDVI, LAI và Prep trong loại bazan Miocen cao hơn hẳn so với ở các loại bazan khác. Trong khi đó, giá trị của các chỉ số $\mathrm{Fe}$ (III), Carbonate, $\mathrm{BU}$ và Temp trong cảnh quan bazan Miocen thấp hơn hẳn so với hai cảnh quan còn lại. Các đặc điểm sinh-địahóa trong các cảnh quan bazan Pliocene Pleistocen giữa và Pleistocen muộn khó phân tách hơn so với trong cảnh quan bazan Miocen, đặc biệt là trong trường hợp của các chỉ số $\mathrm{Fe}$ (II), GSI, FAPAR, FVC và LAI.

\subsection{Phân tích mối quan hệ giữa các biến tụt nhiên - xã họi theo mô hình SEM}

Hình 4 trình bày mạng lưới SEM thể hiện các mối quan hệ một chiều giữa các điều kiện tự nhiên trong ba lọa địa hình bazan. Phiên bản SEM này được lọc qua nhiều vòng lặp để loại bỏ các biến có tương quan thấp. Ví dụ như ba biến: "Lượng mưa" (Số 13), "FVC" (Số 16) và "LAI" (số 15) đã bị loại do tương quan kém với các chỉ số khác. Trong phiên bản cuối cùng, mối tương quan giữa 13 biến được tính lại và được phân loại thành 3 lớp bao gồm: lớp (1) với các biến số thạch học (ví dụ $\mathrm{Fe}_{2}+, \mathrm{Fe}_{3}+, \mathrm{Fe}_{2} \mathrm{O}_{3}$, Laterite, Silicate và Carbonate), lớp (2) với các chỉ số điều kiện sinh thái (ví dụ CI, FAPAR, Temp và GSI) và lớp (3) với các nhân tố sử dụng đất (ví dụ: NDVI, NDWI và BU). Theo đó, mô hình SEM (2) hoàn toàn thể hiện được mối quan hệ từ thạch học và điều kiện sinh thái tới hiện trạng sử dụng đất thuộc ba loại địa hình bazan. Các nhân tổ thạch học ở lớp (1) quyết định các đặc điểm sinh thái (lớp 2). Nhờ những đặc trưng về thạch học và sinh thái ở 2 lớp trên, nhà quản lý sẽ quyết định các chính sách sử dụng đất ở lớp số 3 . Qua đó, mô hình SEM đã làm rõ được mối quan hệ thẳng đứng từ tầng đá mẹ, vỏ phong hóa tới tầng thổ nhưỡng, sinh cảnh và tới hoạt động của con người.

\subsection{Xu hướng sủ dụng đất trên địa hình bazan}

\section{a.Xu hướng sử dụng đất trên thành tạo bazan Miocen}

Kết quả nghiên cứu chỉ ra rằng quá trình phong hóa của $\mathrm{Fe}$ (II) và tầng laterit từ đá bazan Miocen mạnh hơn tại các loại đá bazan khác (Hình 3). Các vật liệu phong hóa tại bazan Miocen phân bố có tính đồng nhất, tạo một lớp đất dày, độ đặc thấp và kích thước hạt nhỏ. Lớp vật liệu này hình thành dọc theo các khe nứt và đứt gãy kiến tạo. Đặc biệt, tầng vật liệu này chứa một lượng bauxite tiềm năng để khai thác khoáng sản. Các vật liệu còn lại sau khai khoáng có thể được sử dụng để trồng rừng. Tuy nhiên, nếu không có giải pháp hoàn nguyên, hoàn thồ tốt, tầng thổ nhưỡng có thể không được hoàn trả, dẫn đến nguy cơ giảm độ phì của đất. Đá mẹ hoặc tầng phong hóa saprolit sẽ lộ ra trên bề mặt đất, gây khó khăn cho phát triển nông - lâm nghiệp trong loại địa hình bazan này. Chẳng hạn, dự án Nhân Cơ và Tân Rai chỉ hoàn thổ đầy đủ được 2 ha trong 36 ha trong suốt thời gian khai thác tại Bảo Lộc, tỉnh Lâm Đồng. Đất trong các mỏ bauxite này (khoảng 2 ha) đã được bón phân để trồng rừng keo nhưng cây phát triển khá chậm chạp [5].

So với địa hình bazan Pliocen-Pleistocen giữa, quá trình kiến tạo và xói mòn do nước ở bazan Miocen mạnh hơn đáng kể, dẫn đến giảm mực nước ngầm [14]. Điều này gây khó khăn trong việc cung cấp nước ngọt cho phát triển nông nghiệp và đô thị. Ngoài ra, lượng mưa lớn được ghi nhận ở bazan Miocen (Hình 3), đặc biệt trong mùa mưa đã tạo ra dòng chảy mặt lớn trong thời gian ngắn trên vùng đất dốc, làm tăng tần suất trượt lở và xói mòn đất [2]. Bên cạnh đó, do độ phân cắt sâu trên địa hình bazan Miocen lớn, một lượng lớn nước ngầm đã được thoát ra và chuyển xuống các sông suối về hạ lưu. Nhìn chung, khả năng lưu trữ nước ngầm không đồng nhất theo cả hai chiều ngang và dọc. Hơn nữa, cả nguồn nước mặt và nước ngầm trong cảnh quan bazan Miocen có thể bị ô nhiễm do khai thác khoáng sản, thể hiện ở giá trị của độ đục của 
nước tăng lên theo các kết quả phân tích viễn thám. Tình trạng này được thấy ở cả hai tỉnh Đồng Nai và Lâm Đồng. Do đó, việc áp dụng các chỉ số viễn thám để giám sát chất lượng nước trong cảnh quan bazan Miocen có thể cung cấp thông tin rất hữu ích cho việc quản lý khai thác bauxite theo hướng phát triển bền vững.

Các kết quả xác định xu hướng sử dụng đất trên 3 loại địa hình bazan và 3 loại hình sử dụng đất chính trên các thành tạo bazan tại Đồng Nai và phụ cận được thể hiện trên hình 5 . Xu hướng sử dụng đất theo hướng ưu tiên bảo tồn tự nhiên chỉ được áp dụng tại địa hình bazan Miocen. Xu hướng phát triển kinh tế - xã hội (cây công nghiệp dài ngày, khu dân cư) được tập trung cho 2 loại địa hình bazan còn lại. Việc phát triển các khu dân cư sinh thái cũng được nhận định tại địa hình bazan Miocen, mặc dù diện tích không lớn.

b. Xu hướng sử dụng đất trên thành tạo địa hình bazan Pliocen - Pleistocen giũa

Tại địa hình bazan Pliocen - Pleistocen giữa, đất (gồm cả tầng phong hóa trên cùng) có độ dốc nhỏ hơn $25^{0}$ và dày trên $10 \mathrm{~m}$, phù hợp cho phát triển cây công nghiệp dài ngày (kết quả từ Hình 3). Ví dụ, cây cao su được trồng trên địa hình bazan này thường khá thưa thớt, cách đều nhau và thẳng hàng. Trước đây, cây cao su được sử dụng cho mục đích khai thác mủ cao su. Tuy nhiên, tại một số khu vực, người dân địa phương hiện đang trồng với mục đích khai thác gỗ do có hiệu quả kinh tế cao hơn [15] (khoảng 200-300 triệu đồng/ha - phỏng vấn dân địa phương năm 2019). Do đó, cây cao su thường bị đốn hạ cứ sau 3-5 năm, để lại bề mặt đất trống trong thời gian trước khi cây trưởng thành [16]. Việc phỏng vấn năm 2019 từ các nhà quản lý địa phương tại tỉnh Đồng Nai cho thấy gỗ đã được thu hoạch vào cuối năm 2016 và cây cao su mới chỉ được trồng lại trong năm 2017. Kết hợp với sự tích lũy sắt và nhôm trên các bề mặt bazan, đất nông nghiệp trong hai hoặc ba năm sau mùa thu hoạch vẫn chưa được phủ màu xanh, thể hiện trên ảnh như vùng đất trống. Sự biến đổi sử dụng đất này khiến bề mặt đất nóng hơn so với đất được sử dụng vào mục đích trồng cây công nghiệp dài ngày truyền thống, được minh chứng bởi chỉ số xây dựng xác định dựa trên nhiệt độ bề mặt. Do đó, các giá trị của chỉ số xây dựng trong vùng đất nông nghiệp trong cảnh quan bazan Pliocene Pleistocen giữa sẽ cao hơn các vùng đất khác (Hình 3).

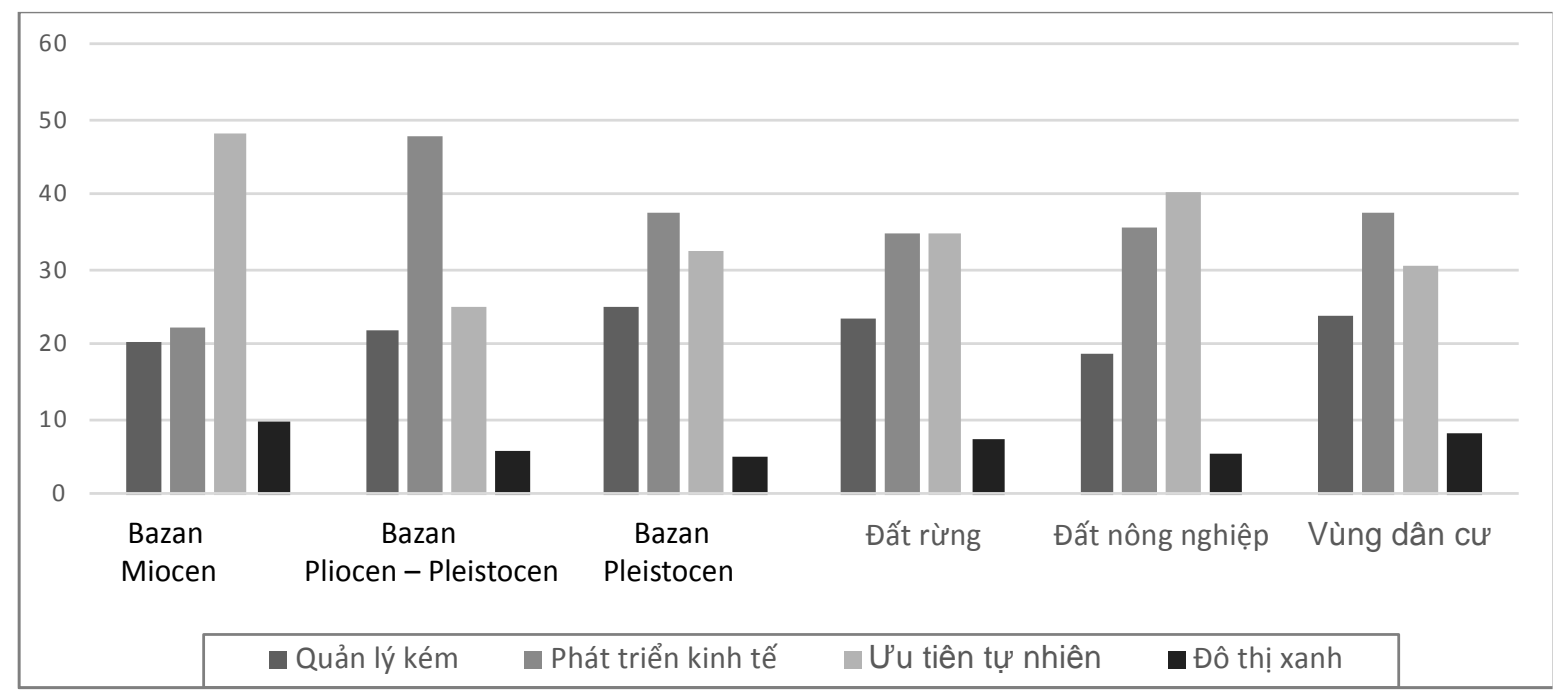

Hình 5. Đánh giá xu thế sử dụng đất trên 3 địa hình bazan và 3 loại hình sử dụng đất chính trên vùng bazan Đồng Nai. Đơn vị \%. 
Ngoài ra, vì cây cao su có thể lưu giữ một lượng carbon lớn, nhiều quốc gia đã mở rộng diện tích của loài này để góp phần hạn chế sự gia tăng khí nhà kính. Trong giai đoạn $80-90$ của thế kỷ 20, diện tích rừng nguyên sinh trong cảnh quan bazan dần bị thu hẹp, thay vào đó là diện tích của cây cao su [1]. Các chính sách ngày nay cũng đang cố gắng làm giảm xu hướng này, nhằm ổn định diện tích rừng trồng và cây công nghiệp. Nó tạo ra một xu hướng quản lý sử dụng đất tốt trên các dạng địa hình bazan PliocenPleistocen giữa ngày nay.

\section{c. Xu hướng sử dụng đất trên thành tạo bazan Pleistocen muộn}

Trên địa hình bazan Pleistocen muộn, quá trình phong hóa yếu, chỉ hình thành một lớp đất mỏng xen giữa các tảng đá gốc. Do đó, loại địa hình này không có nhiều tiềm năng để phát triển cây công nghiệp và các hoạt động nông nghiệp khác. Tuy nhiên, độ nứt nẻ cao của đá đã tạo nguồn nước ngầm lớn, cung cấp nước cho các dòng suối. Tại khu vực phía đông Tân Phú, một nguồn nước có lưu lượng đáng kể được thoát ra từ tầng đá bazan, tạo nên các thác nước có giá trị thẩm mĩ và được người dân tận dụng đề phát triển du lịch sinh thái, điển hình là khu du lịch Suối Mơ, Đồng Nai. Ngoài ra, nhiều hang động núi lửa chỉ được tìm thấy trong các loại địa hình bazan Pleistocen muộn cho thấy tính đặc thù, độc đáo của khu vực. Những hang động này không chỉ cung cấp lợi ích về giá trị khoa học, mà còn cho sự phát triển kinh tế, đặc biệt là phát triển du lịch. Khu vực này có thể tiếp tục nghiên cứu xây dựng công viên địa học phục vụ phát triển du lịch. Các nhà quản lý nên cải thiện các lớp đất trên bề mặt và điều kiện sinh thái trên địa hình bazan Pleistocen muộn, hướng tới mục tiêu phát triển bền vững trong tương lai.

\section{Kết luận}

Trong phạm vi tỉnh Đồng Nai phân bố 4 loại địa hình bazan liên quan với các hệ tầng Đại Nga, Túc Trưng, Xuân Lộc và Phước Tân. Bazan hệ tầng Phước Tân có tuổi trẻ nhất Việt Nam, có thể kéo dài từ Pleistocen muộn tới Holocen với nhiều cảnh quan thiên nhiên đặc sắc. Do địa hình, vỏ phong hóa và đặc điểm sử dụng đất trên bazan các hệ tầng Túc Trưng, Xuân Lộc ở Đồng Nai ít có sự khác biệt, chúng được gộp với nhau trong nghiên cứu này.

Đặc điểm sinh-địa-hóa trên ba loại địa hình bazan đã được đánh giá theo 16 chỉ tiểu dựa trên ảnh viễn thám và yếu tố sử dụng đất/lớp phủ tại tỉnh Đồng Nai. Mối quan hệ các biến số sử dụng/che phủ, địa chất, thạch học, khí hậu, môi trường và đất đai đã được đơn giản hóa thông qua phân tích tương quan và mô hình SEM.

Kết quả đánh giá sinh - địa - hóa trên ba loại địa hình bazan là cơ sở cho việc định hướng quản lý, sử dụng đất khác nhau. Trên địa hình bazan Miocen nên khuyến khích bảo tồn, bảo vệ để có cảnh quan tự nhiên. Trên địa hình bazan Pliocene - Pleistocen giữa, nên tập trung phát triển nông nghiệp gắn với bảo vệ cảnh quan. Đối với địa hình bazan Pleistocen muộn, các chính sách liên quan đến cải tạo đất nên được thực hiện nhằm cải thiện độ phì nhiêu của đất trong tương lai, khuyến khích các khu bảo tồn, phát triển du lịch sinh thái trên các cảnh quan bazan đặc sắc.

\section{Lời cảm ơn}

Nghiên cứu này được tài trợ bởi Đại học Quốc gia Hà Nội trong đề tài mã số QG.17.23. Tập thể tác giả xin chân thành cảm ơn.

\section{Tài liệu tham khảo}

[1] N. Hoang, F. Martin, Petrogenesis of Cenozoic Basalts from Vietnam: Implication for Origins of a Diffuse Igneous Province, J. Petrol. 39 (1998) 369395.

[2] N. Dao, N. Yem, N. Tuyet, L. Tam, Geomorphological features of the basalt areas in the South Vietnam, J. Geol. 172 (1986) 17-20.

[3] A.N. Dang, A. Kawasaki, Integrating biophysical and socio-economic factors for land-use and landcover change projection in agricultural economic regions, Ecol. Modell. 344 (2017) 29-37.

[4] V.B. Dang, Researching on scientific basis to enhance regional linkage between the Central Highlands with the South Central Coast in the use of natural resources, environmental protection and 
disaster prevention, A report in national project No.TN3/T19, Hanoi, 2015 (In Vietnamese).

[5] N.T. Thuy, L.T. Anh, Assessment of Basalt Soil Quality under Different Land Use Types in Bao Loc - Di Linh Area, Lam Dong Province, VNU J. Sci. Earth Environ. Sci. 33 (2017) 67-78 (In Vietnamese).

[6] A. Polydoros, C. Cartalis, Assessing the impact of urban expansion to the state of thermal environment of peri-urban areas using indices, Urban Clim. 14 (2015) 166-175.

[7] R. Fensholt, I. Sandholt, M.S. Rasmussen, Evaluation of MODIS LAI, fAPAR and the relation between fAPAR and NDVI in a semi-arid environment using in situ measurements, Remote Sens. Environ. 91 (2004) 490-507.

[8] S.S. Bhatti, N.K. Tripathi, Built-up area extraction using Landsat 8 OLI imagery, GIScience Remote Sens. 51 (2014) 445-467.

[9] M. Weiss, F. Baret, S2ToolBox Level 2 products: LAI, FAPAR, FCOVER, Sentin. ToolBox Level2 Prod., 2016.

[10] J. Mitchell, R. Shrestha, C. Moore-Ellison, and N. Glenn, Single and Multi-Date Landsat
Classifications of Basalt to Support Soil Survey Efforts, Remote Sens. 5 (2013) 4857-4876.

[11] K.W. Abdelmalik, Landsat 8: Utilizing sensitive response bands concept for image processing and mapping of basalts, Egypt. J. Remote Sens. Sp. Sci., In press (2019).

[12] D.T. Nguyen, Geological map in Vinh An on the scale of 1:50.000, Geological Archives, 1998.

[13] P. Spirtes, C. Glymour, R. Scheines, Causation, Prediction, and Search. London, England: The MIT Press, Cambridge, Massachusetts, 2000.

[14] K.C. Vu, T. Thu, H. Hoang, Histrorical land use dynamics in the Northern mountain of Vietnam, Third Conf. GIS-based Glob. Hist. from Asian Perspect. (2015) 38-43.

[15] W. Killmann, L.T. Hong, Rubberwood - The success of an agricultural by -product, Unasylva 51 (2000) 66-72.

[16] E.S. Nambiar, C.E. Harwood, N.D. Kien, Acacia plantations in Vietnam: research and knowledge application to secure a sustainable future, South. For. 77 (2015) 1-10. 